\title{
Rash induced by enteral vancomycin therapy in an older patient in a long-term care ventilator unit: case report and review of the literature
}

\author{
Jeremy Barron ${ }^{1,2^{*}}$, Adolfo Lattes ${ }^{1}$ and Esther-Lee Marcus ${ }^{1}$
}

\begin{abstract}
Background: Oral vancomycin is a first-line treatment for severe Clostridium difficile colitis. Oral vancomycin is perceived to lack systemic absorption or systemic adverse effects; however, a few cases of hypersensitivity to oral vancomycin have been reported, all in hospitalized patients.

Case presentation: In the present case, a 66-year-old woman with end-stage neurodegenerative disease residing in a long-term care facility developed a maculopapular rash following treatment with enteral vancomycin for recurrent C. difficile colitis. The rash resolved after withdrawal of the drug.

Conclusion: Rashes associated with oral vancomycin treatment include maculopapular rash, urticaria, red man syndrome, and linear IgA bullous dermatitis. Risk factors for systemic vancomycin absorption include renal insufficiency, severe intestinal inflammation, and high vancomycin dose and duration. Routine serum testing of vancomycin levels, even in these high risk cases, is not recommended. Clinicians should be aware that enteral vancomycin can cause hypersensitivity reactions which may be serious.
\end{abstract}

Keywords: Drug hypersensitivity, Clostridium difficile colitis, Vancomycin

\section{Background}

Clostridium difficile remains an important infection in long-term care facilities, contributing to morbidity and mortality [1]. Orally administered vancomycin, generally an effective treatment for $C$. difficile colitis, is perceived to lack the risk of systemic adverse drug reactions or hypersensitivity reactions seen with intravenous administration. However, there have been 11 published cases of cutaneous reactions to enteral vancomycin [2-12] (Table 1). We present a case of hypersensitivity to enteral vancomycin in a long-term care facility. The patient's legal representative provided consent for publication of this case.

\footnotetext{
*Correspondence: jbarron5@jhmi.edu

${ }^{1}$ Chronic Ventilator Unit, Herzog Medical Center, Givat Shaul St, POB

3900, 91035 Jerusalem, Israel

Full list of author information is available at the end of the article
}

\section{Case presentation}

A diabetic, chronically ventilated woman in her late $60 \mathrm{~s}$ with end-stage neurodegenerative disease, residing in a long-term care ventilator unit, developed diarrhea that was positive for $C$. difficile toxin 1 month after treatment with a first-generation cephalosporin for cellulitis. She began enteral metronidazole per gastrostomy tube, but diarrhea continued. She was switched to enteral vancomycin. The diarrhea stopped, but recurred 2 weeks later, associated with low-grade fever, leukocytosis, hyperglycemia, and hypoalbuminemia. Enteral vancomycin was restarted (125 $\mathrm{mg}$, four times/day) and diarrhea improved.

On day 4 of treatment, red macules, papules and patches appeared on her thighs, torso, and back. The neck and upper extremities were generally unaffected and there was no mucous membrane involvement. She was afebrile $\left(36.0^{\circ} \mathrm{C}\right)$, her pulse was 95 beats-per-minute 
Table 1 Published cases of reactions to oral vancomycin

\begin{tabular}{|c|c|c|c|c|c|c|}
\hline Reference & Sex & Age & Reaction & $\begin{array}{l}\text { Vancomycin dose, } \\
\text { treatment duration } \\
\text { before rash }\end{array}$ & $\begin{array}{l}\text { Vancomycin serum } \\
\text { level }\end{array}$ & Risk factors \\
\hline Bailey et al. [2] & $M$ & 82 & Red man syndrome & 250 mg every 6 h, 4 days & Not done & $\begin{array}{l}\text { Acute on chronic } \\
\text { kidney disease, high } \\
\text { vancomycin dose }\end{array}$ \\
\hline Baumgartner et al. [3] & $M$ & 51 & Maculopapular rash & 125 mg every 6 h, 3 days & Not done & Diverticulitis, severe CDI \\
\hline Bergeron et al. [4] & $M$ & 23 months & Red man syndrome & 90 mg every 6 h, first day & $28.7 \mathrm{mcg} / \mathrm{mL}$ & $\begin{array}{l}\text { Multiple drug } \\
\text { hypersensitivities }\end{array}$ \\
\hline Bossé et al. [5] & M & 35 & Anaphylaxis & 500 mg, first dose & Not done & $\begin{array}{l}\text { Cystic fibrosis, multiple } \\
\text { hypersensitivities-IV } \\
\text { vancomycin } \\
\text { hypersensitivity, severe } \\
\text { CDI }\end{array}$ \\
\hline Choudhry et al. [6] & F & 60 & $\begin{array}{l}\text { Linear IgA bullous } \\
\text { dermatosis }\end{array}$ & Unknown dose, 14 days & Not reported & $\begin{array}{l}\text { Prolonged duration of } \\
\text { treatment }\end{array}$ \\
\hline Killian et al. [7] & $F$ & 67 & Red man syndrome & $\begin{array}{l}500 \text { mg every } 6 \text { h, first } \\
\text { day }\end{array}$ & $4.1 \mathrm{mcg} / \mathrm{mL}$ & High vancomycin dose \\
\hline McCullough et al. [8] & $\mathrm{F}$ & 82 & Maculopapular rash & 125 mg every 6 h, 8 days & Not done & Chronic kidney disease \\
\hline Mizumura et al. [9] & $M$ & 76 & Maculopapular Rash & 500 mg every 6 h, 9 days & $3.9 \mathrm{mcg} / \mathrm{mL}$ & $\begin{array}{l}\text { High vancomycin dose, } \\
\text { severe CDI }\end{array}$ \\
\hline Nallasivan et al. [10] & $M$ & 58 & Red man syndrome & Dose not reported, 3 days & Not done & $\begin{array}{l}\text { Acute kidney injury } \\
\text { requiring dialysis, ICU } \\
\text { care }\end{array}$ \\
\hline O’Brien et al. [11] & $M$ & 45 & $\begin{array}{l}\text { Linear IgA bullous } \\
\text { dermatosis }\end{array}$ & Unknown dose, 2 days & Not reported & End stage renal failure \\
\hline Osawa et al. [12] & $F$ & 73 & Maculopapular rash & $\begin{array}{l}250 \text { mg, first day after } \\
\text { completing oral } \\
\text { desensitization }\end{array}$ & Not done & $\begin{array}{l}\text { IV vancomycin } \\
\text { hypersensitivity, recent } \\
\text { colon perforation }\end{array}$ \\
\hline Current report & $\mathrm{F}$ & 66 & Maculopapular rash & 125 mg every 6 h, 4 days & $0.1 \mathrm{mcg} / \mathrm{mL}$ & \\
\hline
\end{tabular}

$\mathrm{CDI}$, Clostridium difficile infection; $\mathrm{d}$, days; f, female; $\mathrm{h}$, hour; $\mathrm{m}$, Male

(bpm) and blood pressure was 125/70 $\mathrm{mmHg}$. Cardiac and pulmonary examinations were unremarkable. Her abdominal examination showed no organomegaly and there was no change from baseline in the neurological examination. White blood count (WBC) was $7.500 / \mathrm{mL}$ with $73 \%$ neutrophils, $20 \%$ lymphocytes, $5 \%$ monocytes, and $2 \%$ eosinophils. Renal function tests were subtly elevated (creatinine $0.3 \mathrm{mg} / \mathrm{dL}$ vs. $0.16 \mathrm{mg} / \mathrm{dL}$ baseline and blood urea nitrogen $6.7 \mathrm{mmol} / \mathrm{L}$ [normal range 2.5$6.4 \mathrm{mmol} / \mathrm{L}])$. Her blood glucose level was $255 \mathrm{mg} / \mathrm{dL}$ and albumin dropped from $3.0 \mathrm{~g} / \mathrm{dL}$ to $2.3 \mathrm{~g} / \mathrm{dL}$. Gammaglutamyltransferase (GGT) was $191 \mathrm{IU} / \mathrm{L}$ (normal range 5-85 IU/L) alkaline phosphatase 223 IU/L (normal range 46-116 IU/L); and transaminases (aspartate transaminase [AST] $50 \mathrm{IU} / \mathrm{L}$ [normal range 15-37 IU/L] and alanine transaminase [ALT] $93 \mathrm{IU} / \mathrm{L}$ [normal range 12-78 IU/L]) were slightly elevated. Elevated liver enzymes were not a new finding.

The only changes in treatment in the days preceding the rash were introduction of vancomycin and insulin, which she had received in the past, and a change in the brand of food administered through her gastrostomy tube. Her other medications were ipratropium, zolpidem, trazodone, potassium gluconate, moxifloxacin eye drops, artificial tears, and oxycodone/acetaminophen. After the rash appeared, vancomycin was stopped. Metronidazole was restarted with a dose of $500 \mathrm{mg}$ three times/day and diarrhea slowly abated. Her rash was treated symptomatically with systemic antihistamines (chlorpheniramine), resolving within 3 days. Other medications were continued, including the new tube feeding brand. Her serum vancomycin level when the rash occurred was $0.1 \mathrm{mcg} / \mathrm{mL}$. The rash did not recur and she was not rechallenged with vancomycin because her diarrhea responded to metronidazole. No other patients or staff members had similar rashes. There was no infectious outbreak at the time in the unit. As noted, her rash was not associated with fever and was also not associated with other viral or autoimmune symptoms. According to the Naranjo Adverse drug reaction probability scale [13], this rash was a probable reaction to vancomycin (score 6/13). 


\section{Discussion and conclusions}

We present a case of a maculopapular rash in a chronically-ventilated woman with end-stage neurodegenerative disease, residing in a long-term care facility. The rash developed 4 days after initiation of enteral vancomycin treatment for $C$. difficile diarrhea. Several cases of oral vancomycin skin reactions have been reported, all in acute-care hospitals (see Table 1) [2-12], most in patients over age 60.

Reactions have included anaphylaxis, red man syndrome, linear IgA bullous dermatitis, and maculopapular rash. Red man syndrome is characterized by a red rash, predominantly on the head and upper body following vancomycin administration. It is caused by mast cell degranulation rather than by IgE-mediated allergy. Vancomycin-induced linear IgA bullous dermatosis is characterized by tense grouped bullae and caused by IgA deposits at the dermo-epidermal junction [6].

Other than IgA bullous dermatosis, other nonimmediate vancomycin hypersensitivity reactions can include DRESS syndrome (drug reaction with eosinophilia and systemic symptoms), acute interstitial nephritis, and Stevens-Johnson syndrome [14]. These other hypersensitivity reactions have not been reported after enteral vancomycin use. Only one case of an IgEmediated reaction to enteral vancomycin has been reported [5], but it can be difficult to differentiate IgEmediated hypersensitivity reactions from red man syndrome [14].

Studies have not detected serum vancomycin levels in healthy populations receiving oral vancomycin [15]; however, several studies have identified detectable vancomycin levels in individuals with $C$. difficile infection, presumably reflecting the impact of gastrointestinal tract inflammation. Although enteral administration of vancomycin minimizes systemic absorption, 58 of 85 participants who received enteral vancomycin in one study of patients with $C$. difficile had a detectable serum vancomycin level $\geq 0.05 \mathrm{mcg} / \mathrm{mL}$ [16]. The frequency of detectable serum vancomycin levels in patients receiving oral treatment has varied from $2 \%$ to $68 \%$ in published studies [16-18].

Risk factors for systemic absorption of oral vancomycin in one study include renal insufficiency, severe $C$. difficile (age 65 and above is one criteria for that category, according to some definitions), high vancomycin dose (>500 $\mathrm{mg} /$ day), prolonged therapy (>10 days), ICU admission, use of vancomycin retention enemas, and GI tract inflammation [16]. Among published cases of oral vancomycin reactions, most patients had at least one of these risk factors. Several patients also had a history of other hypersensitivities or cystic fibrosis, both general risk factors for drug hypersensitivity. In one study, prolonged fasting and massive diarrhea were risk factors for systemic absorption [19].

Systemic vancomycin has been associated with cutaneous adverse reactions. Younger age and prolonged duration of therapy were risk factors for cutaneous adverse reactions in an older study [20], and they accounted for almost half of adverse drug reactions from systemic vancomycin in one report [21].

Because $C$. difficile infections as well as $C$. difficile infection severity both seem to be increasing [22], oral vancomycin will likely be prescribed more frequently and more adverse reactions will be seen. Nevertheless, routine serum vancomycin testing for patients receiving oral vancomycin is not recommended because serum levels in a toxic range are unlikely to be found.

Rechallenge with a suspected source of a drug rash is helpful to confirm the cause of hypersensitivity. In our patient and in many other clinical cases, rechallenge was not performed because alternative pharmacotherapy was available, safe, and effective; thus the risk-benefit ratio did not justify rechallenge [23].

In cases of cutaneous vancomycin reactions, stopping the drug is the key first step of treatment [24]. In a patient with no systemic reaction and no suggestion of immediate hypersensitivity, treating a maculopapular rash with antihistamines while continuing vancomycin may be a reasonable strategy when no alternative treatments are available. This approach has been used successfully with other anti-microbial agents [25].

Management choices for patients with $C$. difficile infection and an intolerance to oral vancomycin could include vancomycin desensitization (which can utilize intravenous doses [26] or oral administration [27]. A successful case of oral vancomycin desensitization over $5 \mathrm{~h}$ to treat severe $C$. difficile colitis has been reported [27]. Another option is the use of other treatments such as metronidazole, fidaxomicin, or fecal transplant [28, 29].

Oral vancomycin is used commonly in clinical practice in hospitals as well as in long-term care facilities, and clinicians should be aware of the possibility of systemic adverse effects, including anaphylaxis.

\footnotetext{
Authors' contributions

All three of the authors made significant contributions to conception and design of this case report and all three authors were involved in drafting or revising the manuscript. All authors read and approved the final manuscript.

\section{Author details}

${ }^{1}$ Chronic Ventilator Unit, Herzog Medical Center, Givat Shaul St, POB 3900, 91035 Jerusalem, Israel. ${ }^{2}$ Department of Medicine, Johns Hopkins University, 5505 Hopkins Bayview Circle, Baltimore, MD 21224, USA.
} 


\section{Acknowledgements \\ None.}

\section{Competing interests}

The authors declare that they have no competing interests.

\section{Availability of data and materials}

Data is from the electronic medical record.

\section{Consent for publication}

The patient's legal guardian provided consent for publication of this case.

\section{Ethics approval and consent to participate}

Not applicable.

\section{Funding}

There was no independent funding for this case report.

\section{Publisher's Note}

Springer Nature remains neutral with regard to jurisdictional claims in published maps and institutional affiliations.

Received: 14 November 2017 Accepted: 17 August 2018

Published online: 06 November 2018

\section{References}

1. Simor AE. Diagnosis, management, and prevention of Clostridium difficile infection in long-term care facilities: a review. J Am Geriatr Soc. 2010;58:1556-64.

2. Bailey P, Gray H. An elderly woman with 'Red Man Syndrome' in association with oral vancomycin therapy: a case report. Cases J. 2008;1:111.

3. Baumgartner LJ, Brown L, Geier C. Hypersensitivity reaction following administration of low-dose oral vancomycin for the treatment of Clostridium difficile in a patient with normal renal function. J Pharm Pract. 2017:30:650-2.

4. Bergeron L, Boucher FD. Possible red-man syndrome associated with systemic absorption of oral vancomycin in a child with normal renal function. Ann Pharmacother. 1994;28:581-4.

5. Bossé D, Lemire C, Ruel J, Cantin AM, Menard F, Valiquette L. Severe anaphylaxis caused by orally administered vancomycin to a patient with Clostridium difficile infection. Infection. 2013:41:579-82.

6. Choudhry SZ, Kashat M, Lim HW. Vancomycin-induced linear IgA bullous dermatosis demonstrating the isomorphic phenomenon. Int J Dermatol. 2015:54:1211-3.

7. Killian AD, Sahai JV, Memish ZA. Red man syndrome after oral vancomycin. Ann Intern Med. 1991;115:410-1.

8. McCullough JM, Dielman DG, Peery D. Oral vancomycin-induced rash: case report and review of the literature. DICP. 1991:25:1326-8.

9. Mizumura N, Demura K, Kawasaki M, Okumura S, Toyoda S, Imagawa A, et al. Continuous administration of vancomycin through a long intestinal tube for Clostridium difficile infection. Intern Med. 2015;54:1559-62.

10. Nallasivan M, Maher F, Murthy K. Rare case of "red man" syndrome in a female patient treated with oral vancomycin for Clostridium difficile diarrhoea. BMJ Case Rep. 2009:2009:bcr03.2009.1705.

11. O'Brien M, Shah A, Allen HB. A pentad of vancomycin reactions. Skinmed. 2011;9:225-9.
12. Osawa R, Kaka AS. Maculopapular rash induced by oral vancomycin. Clin Infect Dis. 2008;47:860-1.

13. Naranjo CA, Busto U, Sellers EM, Sandor P, Ruiz I, Roberts EA, et al. A method for estimating the probability of adverse drug reactions. Clin Pharmacol Ther. 1981:30:239-45.

14. Minhas JS, Wickner PG, Long AA, Banerji A, Blumenthal KG. Immunemediated reactions to vancomycin: a systematic case review and analysis. Ann Allergy Asthma Immunol. 2016;116:544-53.

15. Geraci JE, Heilman FR, Nichols DR, Ross GT, Wellman WE. Some laboratory and clinical experiences with a new antibiotic, vancomycin. Proc Staff Meet Mayo Clin. 1956;31:564-82.

16. Pettit NN, DePestel DD, Fohl AL, Eyler R, Carver PL. Risk factors for systemic vancomycin exposure following administration of oral vancomycin for the treatment of Clostridium difficile infection. Pharmacotherapy. 2015;35:119-26.

17. Armstrong CJ, Wilson TS. Systemic absorption of vancomycin. J Clin Pathol. 1995:48:689

18. Rao S, Kupfer Y, Pagala M, Chapnick E, Tessler S. Systemic absorption of oral vancomycin in patients with Clostridium difficile infection. Scand J Infect Dis. 2011:43:386-8.

19. Oami T, Hattori N, Matsumura Y, Watanabe E, Abe R, Oshima T, et al. The effects of fasting and massive diarrhea on absorption of enteral vancomycin in critically ill patients: a retrospective observational study. Front Med. 2017:4:70

20. Korman TM, Turnidge JD, Grayson ML. Risk factors for adverse cutaneous reactions associated with intravenous vancomycin. J Antimicrob Chemother. 1997:39:371-81.

21. An SY, Hwang EK, Kim JH, Kim JE, Jin HJ, Jin SM, et al. Vancomycinassociated spontaneous cutaneous adverse drug reactions. Allergy Asthma Immunol Res. 2011;3:194-8.

22. DePestel DD, Aronoff DM. Epidemiology of Clostridium difficile infection. J Pharm Pract. 2013;26:464-75

23. Aberer W, Bircher A, Romano A, Blanca M, Campi P, Fernandez J, et al. Drug provocation testing in the diagnosis of drug hypersensitivity reactions: general considerations. Allergy. 2003;58:854-63.

24. Sanchez-Borges M, Thong B, Blanca M, Ensina LF, Gonzalez-Diaz S, Greenberger PA, et al. Hypersensitivity reactions to non beta-lactam antimicrobial agents, a statement of the WAO special committee on drug allergy. World Allergy Organ J. 2013;6:18

25. Strazzula L, Pratt DS, Zardas J, Chung RT, Thiim M, Kroshinsky D. Widespread morbilliform eruption associated with telaprevir: use of dermatologic consultation to increase tolerability. JAMA Dermatol. 2014;150:756-9.

26. Anne S, Middleton E Jr, Reisman RE. Vancomycin anaphylaxis and successful desensitization. Ann Allergy. 1994;73:402-4.

27. Mahabir S, Lim RY, Fitzpatrick F, Magee C, Keogan M. Oral vancomycin desensitisation to treat Clostridium difficile infection in a vancomycin allergic patient. World Allergy Organ J. 2013;6:16

28. Debast SB, Bauer MP, Kuijper EJ. European Society of Clinical Microbiology and Infectious Diseases: update of the treatment guidance document for Clostridium difficile infection. Clin Microbiol Infect. 2014:20(Suppl 2):1-26.

29. McDonald LC, Gerding DN, Johnson S, Bakken JS, Carroll KC, Coffin SE, et al. Clinical practice guidelines for Clostridium difficile infection in adults and children: 2017 Update by the Infectious Diseases Society of America (IDSA) and Society for Healthcare Epidemiology of America (SHEA). Clin Infect Dis. 2018:66:e1-48. 